\title{
¿Cómo entender la movilidad ocupacional de los migrantes de retorno? Una propuesta de marco explicativo para el caso mexicano*
}

\author{
Salvador Cobo**
}

\section{Introducción}

Conforme a la perspectiva de los países expulsores es necesario construir un marco explicativo que permita entender por qué la migración internacional es un mecanismo asociado a la movilidad ocupacional. Potencialmente las experiencias migratorias pueden proveer activos de capital humano o físico a los migrantes, de tal suerte que tales acumulaciones les facilitarán reinsertarse en mejores empleos al regresar a su país de origen. Dentro de este esquema, el retorno migratorio incide en los mercados de trabajo. El marco explicativo está basado en el caso mexicano, dada la persistencia del retorno migratorio de Estados Unidos.

El presente texto está organizado en cuatro secciones. En la primera se revisan los conceptos y las perspectivas clásicas de la movilidad ocupacional; asimismo se reseña la investigación sobre la materia para el caso de México. En la segunda sección se aborda la importancia de la migración mexicana de retorno y su inclusión en los estudios de movilidad ocupacional. En la tercera parte se construye un marco explicativo sobre las movilidades ocupacionales de los migrantes de retorno a partir de las acumulaciones de capital humano o físico, y su estructuración en función de tres dimensiones analítico temporales. En la cuarta y última se presentan las reflexiones finales, así como los nuevos desafíos para la investigación sociodemográfica.

* Esta nota de investigación es parte de los desarrollos iniciales del proyecto de tesis doctoral del autor. Agradezco los comentarios que Francisco Alba y Manuel Ángel Castillo hicieron a una versión anterior durante el curso de Migración Internacional; asimismo los de dos dictaminadores anónimos que contribuyeron a mejorar el documento.

** Estudiante del programa de doctorado en Estudios de Población del CEDUA, El Colegio de México. Correo electrónico: sdcobo@colmex.mx.

$\overline{\text { ESTUDIOS DEMOGRÁFICOS Y URBANOS, VOL. 23, NÚM. } 1 \text { (67), 2008, 159-177 }}$ 


\section{La movilidad ocupacional en México: conceptos básicos y perspectivas}

El término movilidad social hace referencia a los desplazamientos de los individuos entre dos periodos de tiempo en función de sus estatus socioeconómicos (Birdsall y Graham, 2000). ${ }^{1}$ La movilidad debe estudiarse a partir de la ocupación, ya que existe una estrecha relación de ésta con los ingresos y la escolaridad (Cortés y Escobar, 2003). ${ }^{2}$

Zenteno y Solís (2006) afirman que la vía más común de acceso a los ingresos monetarios es el mercado de trabajo. Las condiciones de vida de la mayoría de la población y su estatus social están determinados por el empleo. La ocupación y sus categorías se han convertido en el marco de referencia de la movilidad social (Solís, 2002).

En términos generales podemos considerar que hay dos formas de estudiar la movilidad ocupacional: intra e intergeneracional. La primera hace alusión a los cambios jerárquicos que un mismo individuo experimenta en dos momentos del tiempo. La segunda compara los logros del informante con los de su padre en un mismo punto (Zenteno, 2003). ${ }^{3}$ Cabe aclarar aquí que el marco explicativo se plantea de manera exclusiva para la movilidad intrageneracional. Las experiencias laborales en el extranjero se entenderán como mecanismos que influyen en los logros ocupacionales de los migrantes cuando regresan a su país de origen. ${ }^{4}$

${ }^{1}$ En los años setenta, la movilidad social atrajo la atención de varios investigadores sociales en América Latina (Solís, 2003 y 2005; Escobar, 2001; Filgueira, 2000). Más tarde hubo un desinterés por el tema; los paradigmas clásicos (estructuralistas) no proveían mayores explicaciones acerca de la estratificación y la movilidad ocupacional. Comenzaron entonces a cobrar importancia los estudios sobre la pobreza y la distribución del ingreso (Filgueira, 2000). En el contexto de los modelos económicos que adoptaron los gobiernos de la región latinoamericana los académicos se han abocado a reflexionar sobre el resurgimiento de la movilidad social. Esencialmente se apunta a incluir enfoques y perspectivas que permitan entender los cambios jerárquicos de la población a partir del funcionamiento de las economías y las heterogeneidades de los mercados de trabajo, pero también desde los mismos individuos. En otras palabras, se demanda profundizar en las características sociodemográficas, en la educación y las formaciones de capital humano y físico en su función de elementos explicativos.

${ }^{2}$ El eje ocupacional es uno de las más desarrollados; sin embargo la educación, los ingresos y los gastos, los emparejamientos conyugales, la participación social y política, y demás medidas de estatus social también forman parte de la cuestión (Behrman, 2000).

${ }^{3}$ Convencionalmente se suele hacer el corte analítico a los 30 años de edad del informante y de su padre.

${ }^{4}$ Dada la historicidad del proceso migratorio entre México y Estados Unidos es posible encontrar familias con largas trayectorias migratorias. Se reconoce la necesidad de incluir en las discusiones futuras la movilidad ocupacional de los padres e hijos migrantes de retorno para entender las implicaciones de las experiencias migratorias de varias generaciones. 
Recientemente la movilidad intra e intergeneracional ha llamado de nueva cuenta la atención de los investigadores sociales. En México los estudios más recientes han demostrado la movilidad ascendente de los hijos respecto a la de sus padres, principalmente en materia educativa, y lo poco que ha sido recompensada la instrucción formal en términos laborales y de ingresos monetarios (Behram, Gaviria y Székely, 2002), el marcado deterioro de las oportunidades de ascenso y permanencia ocupacional de la población a partir de los procesos de liberalización comercial (Cortés y Escobar, 2003), la resistencia de los individuos a permanecer en las mismas ocupaciones de sus padres (Pacheco, 2005) por los efectos negativos que han tenido los contextos económicos posteriores al de industrialización sobre la movilidad ocupacional (Parrado, 2003) y las posibilidades de los jóvenes de obtener ingresos similares o inferiores a los de sus padres (Solís, 2003). ${ }^{5}$

Con las excepciones de Lindstrom y Kim (2002), Papail y Arroyo (2004) y Cobo (2004), aún son escasos los autores que incluyen en sus trabajos a la migración internacional como una de las variables explicativas de los ascensos y descensos laborales de la población con experiencias de trabajo en el extranjero. ${ }^{6}$ Parrado (2003) sostiene que los efectos poco positivos de los periodos neoliberales sobre la movilidad ocupacional de los mexicanos habrían sido más pronunciados sin la emigración internacional como consecuencia de la selectividad negativa de los actores intervinientes, que al no contar con opción de migrar a Estados Unidos hubieran ocupado los espacios de trabajo de menor calificación en el país. Indudablemente este panorama laboral se habría reflejado en los procesos de movilidad.

Conforme a esta lógica los esfuerzos de investigación sobre movilidad ocupacional deberían ser evaluados en función del constante flujo migratorio hacia Estados Unidos para dar un tratamiento consistente al acto migratorio al añadirlo como una potencial explicación. La migración pudo haberse consolidado como mecanismo de movilidad ocupacional entre quienes lograron beneficiarse con la experien-

${ }^{5}$ Zenteno y Solís (2006) argumentan que muchas de las investigaciones recientes fueron posibles gracias a la introducción de preguntas especializadas en las encuestas nacionales; ejemplo de ello es el módulo de "Género, edad, familia y trabajo en el México urbano", incluido en la Encuesta Nacional de Empleo Urbano (ENEU). Asimismo se han llevado a cabo recopilaciones de información con perspectiva de curso de vida. Tales fueron los casos de la Encuesta Demográfica Retrospectiva (Eder) o de la Encuesta sobre Movilidad Social y Curso de Vida en Monterrey.

${ }^{6}$ Estas investigaciones no construyeron un marco explicativo para las movilidades ocupacionales de los migrantes en sus distintas modalidades (ascenso o descenso). 
cia laboral en el extranjero para llevarla a la práctica en los mercados de trabajo de México. Los migrantes de retorno constituyen un ejemplo ideal para comprender la movilidad ocupacional en contextos migratorios.

En la siguiente sección se presenta un panorama general de la migración de retorno en México con la intención de destacar su importancia demográfica y la conveniencia de tomarla en cuenta en el análisis planteado.

\section{Los migrantes de retorno: ¿por qué conviene estudiar su movilidad ocupacional?}

El proceso migratorio entre México y Estados Unidos es complejo; su profunda tradición histórica ha dejado raíces estructurales en ambos lados de la frontera (Papail, 2002; Conapo, 2001; Tuirán, 1997). La migración a Estados Unidos forma parte de las estrategias familiares para diversificar los ingresos de las unidades domésticas. ${ }^{7}$

El proceso migratorio a la inversa (retorno) tiene consecuencias económicas, pues quienes regresan al país de origen pudieron haber realizado inversiones productivas con sus ahorros, o simplemente adquirir nuevas calificaciones laborales que les permiten acceder a mejores ocupaciones en México. ${ }^{8}$

Feindt y Browning (1972) sugerían que en el estudio del proceso migratorio poco se había explorado el regreso de los individuos a su lugar de origen. Hasta esos momentos el fenómeno había sido muy reconocido, pero la variedad de contextos en que se presentaba, su estimación y su significado eran elementos escasamente estudiados. Parrado (2004) especifica que existe un fuerte componente de retorno en los flujos migratorios de mexicanos a Estados Unidos dada la cercanía geográfica entre ambos países.

${ }^{7}$ El efecto de la migración en las sociedades de origen y de destino depende en gran medida del número y perfil de los emigrantes que participan en este flujo. No cabe duda de que la migración mexicana es una corriente masiva de carácter laboral. Es conveniente precisar que los mexicanos que se desplazan a Estados Unidos no constituyen un conjunto homogéneo, sino grupos relativamente diferenciados.

${ }^{8}$ Las inversiones de los migrantes han sido examinadas ampliamente por la investigación social (García Zamora, 2005; Canales, 2005; Durand et al., 1996a). Los proyectos económicos sustentados en las remesas monetarias pueden o no insertarse en un esquema de desarrollo regional o comunitario en el país de origen. Sin embargo las remesas siempre inciden en el bienestar del migrante y de su familia (Canales, 2005). 
En el proceso migratorio mexicano la diferenciación de patrones no es tarea fácil. Las intenciones individuales y las trayectorias ocupacionales de cada uno en Estados Unidos presentan comportamientos heterogéneos (Escobar y Martínez, 1987). Es obvio que para que ocurra un regreso debió haber un desplazamiento de ida.

Consideramos que cualquier individuo que regresó a su lugar de origen, independientemente del tiempo de duración de la experiencia migratoria y del ciclo de vida en el cual ocurra, debe verse como un migrante de retorno. Desde esta perspectiva, el marco interpretativo incluye a todos los que regresan o regresaron a México definitiva o temporalmente después de haber tenido una experiencia migratoria internacional en Estados Unidos. Nos interesa particularmente la vinculación de los migrantes retornados con los mercados de trabajo del país de origen; allí se aplica nuestro planteamiento. ${ }^{9}$

Durand y Massey (2003) aseguran que México es el único país en el mundo que recibe un importante número de migrantes de retorno. Corona (2004) y Corona y Tuirán (2000) han construido estimaciones significativas. A partir de la Encuesta Nacional de la Dinámica Demográfica de 1992 (Enadid 92), estimaron que aproximadamente dos millones y medio de mexicanos habían vivido o trabajado en algún momento en Estados Unidos. Para principios de la década de los noventa, esa cifra representaba $3 \%$ de la población total del país (Corona y Tuirán, 2000).$^{10}$ Más tarde Corona (2004) tomó la versión de la Enadid 97 y reportó que $4 \%$ de la población mexicana de 12 años y más había ido a trabajar o a buscar empleo a Estados Unidos. ${ }^{11}$

A partir de la Encuesta sobre Migración en la Frontera Norte (EMIF) se han generado estimaciones más certeras respecto a los flujos anua-

\footnotetext{
${ }^{9}$ Una variable importante dentro del marco explicativo es la duración del retorno, ya que ésta define los proyectos productivos y los nichos laborales de los migrantes en el país de origen.

${ }^{10}$ En su mayoría los migrantes de retorno eran hombres de 20 a 39 años de edad. Este hallazgo cuestionaba la visión unidireccional del regreso migratorio en edades avanzadas; se demostraba que los jóvenes también regresaban a México después de una experiencia migratoria. En 1992 se estimaba que una de cada diez unidades domésticas presentes en territorio nacional contaba con algún migrante de retorno. Estos hogares se encontraban principalmente en el centro occidente del país (Corona, 2004).

${ }^{11}$ Este ligero incremento (1\%) respecto al retorno estimado en 1992 corresponde a los individuos que migraron a Estados Unidos y regresaron a México entre 1993 y 1997. Las particularidades sociodemográficas se mantuvieron sin modificaciones mayúsculas; siguieron siendo los hombres en edades productivas quienes más participaron en los flujos de retorno. Los hogares del centro occidente mantuvieron una mayor cuantía de individuos con experiencia migratoria internacional en Estados Unidos.
} 
les de migrantes de retorno provenientes de Estados Unidos. ${ }^{12}$ Quienes retornan son en su mayoría hombres; esta situación tiene su correlato en la migración de carácter más permanente de las mujeres. El regreso correspondió en mayores proporciones al grupo de 25 a 34 años (Conapo, 2002 y 2005), de ahí la importancia de conocer su desempeño laboral en los lugares de retorno.

El componente laboral del proceso migratorio entre México y Estados Unidos y la continuidad del retorno hacen indispensable generar conocimientos sistemáticos respecto a la repercusión de las experiencias migratorias en el extranjero sobre las movilidades ocupacionales de los migrantes retornados. Durand (2005) asegura que los migrantes encuentran una opción factible de movilidad social en el contexto de regreso. Aunque el país de origen siga en la misma situación de dependencia y subdesarrollo económico, en el ámbito personal los migrantes podrían acceder a ciertos procesos de movilidad, los cuales se manifiestan en un conjunto de indicadores socioeconómicos, como la compra de casa o automóvil, la posesión de un negocio comercial, la inversión en la educación de los hijos, el incremento en los niveles de consumo, y el acceso a un mejor trabajo.

El marco explicativo se aboca a observar a los migrantes de retorno del sexo masculino, pues ellos son los más propensos a volver al país. Detrás de esta delimitación por sexo se han vertido argumentos sobre la oferta laboral y los mercados de trabajo. Generalmente el análisis del empleo y la determinación de los desplazamientos laborales (movilidades) se realizan en función de las incorporaciones a la fuerza de trabajo. La incursión y la permanencia de los hombres en los mercados de trabajo representan eventos casi universales en el curso de sus vidas. En contraste, tal situación no siempre ocurre con las mujeres. Han sido ampliamente documentadas las discontinuidades y las intermitencias de la fuerza laboral femenina (véase para México los trabajos de Ariza y Oliveira, 2005; Parrado y Zenteno, 2002; Peinador, 2001; Cerruti, 1997; Cruz P., 1994). ${ }^{13}$

${ }^{12}$ Complementariamente, la Encuesta Nacional de Empleo 2002 (ENE) y el módulo de migración internacional del Censo de Población y Vivienda de 2000 brindan evidencia empírica al respecto.

${ }^{13}$ Para incluir a las mujeres sería indispensable construir un marco explicativo específico que examinara las diferencias en la inserción laboral de la fuerza de trabajo femenina en distintas etapas de su vida y el porqué de que algunas mujeres migren y otras no. Asimismo explicaría sus entradas y salidas de los mercados de trabajo, en especial las que ocurren antes y después de un acto migratorio internacional. Adicionalmente deberíamos reflexionar acerca de los significados que las mujeres atribuyen a su participación laboral en el extranjero y su implicación en el regreso al país de origen. 
Las experiencias laborales en el extranjero podrían promover entre los migrantes la adquisición de "nuevos activos", los cuales se sumarían (y en algunos casos podrían restarse) al capital humano o físico que tenían antes de partir. ${ }^{14}$ Eventualmente estos activos podrían ser apreciados en los mercados de trabajo de su lugar de origen al retornar, y el resultado sería una modificación de su estatus laboral. En síntesis, los migrantes pueden experimentar cierta movilidad ocupacional.

El análisis de la movilidad social (intrageneracional) de los migrantes de retorno a México debe centrarse en el trabajo (antes y después de migrar); sin embargo, esta situación podría ser más compleja desde la óptima migratoria, en el sentido de comprender la movilidad social desde otras dimensiones. Los ascensos o descensos socioeconómicos de los migrantes en el país de origen están en función de que hayan comprado terrenos o casas habitación, de que se haya incrementado la participación social y política en los lugares de origen, de las mejorías en los procesos de organización y tecnificación de los negocios familiares, y de la adquisición de capital físico o el uso de maquinaria y herramienta, lo cual les brinda mejores condiciones para la producción. ${ }^{15}$

Dada la importancia de lo laboral entre los migrantes de retorno, el marco interpretativo se refiere a la cuestión ocupacional. Este esquema toma en cuenta tres dimensiones analítico temporales para distinguir la forma en que se estructuran las acumulaciones de "nuevos activos" en los migrantes. Es indudable que la formación de activos

En términos metodológicos esto implica el estudio de los tipos de movilidades ocupacionales que las migrantes de retorno experimentaron en esas entradas y salidas del mercado laboral.

${ }^{14}$ En el contexto latinoamericano se han discutido las implicaciones de la migración laboral en los países expulsores. Altamirano (2004) engloba las posibles ventajas en cuatro puntos: dos de ellas son económicas (la experiencia laboral y el ingreso percibido) y dos sociológicas (la globalización de la cultura, el prestigio y el poder que alcanzan los migrantes en los lugares de origen). El planteamiento del autor gira alrededor de que las economías de origen y destino están relacionadas. El migrante recibe un mayor salario al tener más experiencia laboral, así que mediante los beneficios (salario y aprendizaje laboral de la migración) puede asumir aptitudes y comportamientos diferentes en los lugares de retorno, sobre todo al adquirir habilidades que podrían ser aprovechadas en el marco de las oportunidades económicas del país de origen.

${ }^{15}$ Goldscheider (1987) sostiene que la migración está vinculada a los cambios estructurales. Los migrantes son proveedores de nuevas aptitudes y formas de comportamiento. La migración acarrea transformaciones en los roles sociales y económicos de los miembros de la unidad doméstica, cambios en el acceso a los recursos económicos (mayor disposición de efectivo a partir de las remesas) y en la ocupación del migrante o de algunos de sus parientes. La movilidad intra e intergeneracional es un vínculo entre el proceso migratorio y el desarrollo económico regional. 
está determinada por el tiempo, ya que cada individuo experimenta el acto migratorio y el regreso en distintas etapas. En suma, se conforman en función del curso de vida individual y familiar en que toma la decisión de migrar, de las condiciones en que se desarrollaron sus experiencias laborales en Estados Unidos, y de las oportunidades socioeconómicas que ofrece el lugar de retorno. En las siguientes secciones nos referiremos a los "nuevos activos" de capital humano o físico con que cuentan a partir de la experiencia migratoria.

\section{La migración como forma de acumulación de capital humano o físico}

El proceso migratorio orientado al retorno deja secuelas a lo largo de la vida de los migrantes, sea porque la experiencia laboral o la adquisición de nuevos conocimientos acarrearon cambios en materia laboral, o porque a partir del ahorro o el envío de remesas adquirieron tierras de cultivo o un negocio. A continuación se exponen las diversas formas en que la migración internacional puede ser formadora de activos de capital humano o físico.

\section{Capital humano}

La gran mayoría de los desplazamientos a Estados Unidos obedece a cuestiones de empleo; éstos son más frecuentes entre quienes tienen un objetivo de inversión productiva a su regreso a México (Papail y Arroyo, 2004; Canales, 2002; Cruz, 2002). La migración internacional constituye un mecanismo por medio del cual los individuos incrementan sus habilidades. ${ }^{16}$

La experiencia laboral en el extranjero puede aportar nuevos conocimientos y destrezas en forma de capital humano; tales acumulaciones se manifiestan en el empleo al retorno a México. Esto ocurre porque en Estados Unidos los migrantes están en contacto con otro estilo de vida, aprenden el idioma inglés, conocen otras prácticas de empleo y obtienen cierta calificación laboral.

\footnotetext{
${ }^{16}$ Con la perspectiva de los países expulsores Massey et al. (1998) observan que los migrantes incorporan nuevos conocimientos desde el momento en que inician su aventura migratoria a Estados Unidos, y estos aprendizajes podrían ser aprovechados en las sociedades de destino.
} 
Sin embargo algunas de las destrezas laborales que adquieren podrían no representar una mayor capacidad productiva en sus lugares de origen (Conway y Cohen, 1998). El capital humano puede ser de poca utilidad dentro de la dinámica laboral del país de origen. Asimismo los empleadores nacionales podrían resistirse a contratar fuerza de trabajo con experiencia migratoria internacional ante la posibilidad de que volviera a emigrar. El espectro de la movilidad ocupacional de los migrantes de retorno está vinculado con las oportunidades socioeconómicas del lugar de origen.

\section{Capital físico}

Los individuos reciben un salario por la prestación de su fuerza de trabajo en los lugares de destino. Buena parte la ahorran o la envían en forma de remesas a su país de origen. La migración hacia Estados Unidos es una atractiva forma de adquirir capital con el ahorro de una parte de los salarios que se reciben en dicho país (Singer et al., 1995, y Taylor, 1987, citados en Durand et al., 1996a).

Con frecuencia la migración internacional resulta una estrategia para adquirir capital físico, para incrementar el consumo del grupo doméstico del migrante o para financiar nuevas formas de producción económica (Durand et al., 1996b). Dentro de este esquema la experiencia laboral en el extranjero significaría una oportunidad para emprender un negocio propio o adquirir tierras para el cultivo.

En el siguiente apartado se expone el marco explicativo propuesto para entender la movilidad ocupacional de los migrantes de retorno a México con base en las dimensiones analítico temporales.

\section{El curso de vida individual y familiar y su conexión con la movilidad ocupacional (dimensiones analítico temporales)}

El enfoque de curso de vida es indispensable en la investigación sociodemográfica. Dicha perspectiva ofrece elementos para determinar si algunos eventos sociodemográficos incentivan o no la decisión de migrar y, por ende, sus efectos o repercusiones individuales y familiares.

Específicamente Massey et al. (1991) manifiestan que los cambios en la migración durante el ciclo de vida individual y familiar se asocian con el número de dependientes en el hogar. El número de emigrantes 
por trabajador varía a la inversa del número de trabajadores en la familia. Al nacer los hijos aumenta la posibilidad de que los padres se vayan a Estados Unidos. Cuando los hijos crecen, los padres migran con menos frecuencia y la emigración de los hijos aumenta. En concordancia con estos patrones, los gastos en artículos de consumo son más comunes en las etapas iniciales del hogar, mientras que los gastos por habitación y manutención dominan en las etapas siguientes.

El curso de vida individual y familiar del migrante, primer factor analítico temporal, influye en el consumo y en las necesidades y, por lo tanto, en la disponibilidad de invertir el ahorro o las remesas. Los migrantes casados, particularmente con hijos pequeños, tienen mayores requerimientos económicos de su descendencia. En conclusión, los ahorros de los migrantes en etapas de expansión familiar tienden a dedicar más sus ahorros al consumo y menos a la inversión (Mooney, 2004).

La edad, el estado civil y las tasas de dependencia del hogar están asociados al ahorro derivado de la estancia del trabajador en Estados Unidos, con el cual podría adquirir tierras de cultivo o emprender un negocio comercial al regresar a México. Desde la lógica de la movilidad ocupacional, la inversión productiva de las remesas monetarias está orientada según el curso de vida individual y familiar (Warnes, 1992, citado en Conway y Cohen, 1998).

Los migrantes jóvenes y solteros que forman parte de hogares de pocos miembros son más propensos a utilizar las remesas en el financiamiento de su unión conyugal, en el pago de algunas festividades locales o en el viaje migratorio de otro pariente. En cambio los migrantes que se hallan en unión conyugal son más proclives a comprar tierras cultivables, una casa-habitación o a pagar la educación de los hijos (Conway y Cohen, 1998). Al combinar este factor con la duración de la estancia migratoria observamos que cuanto más se prolongan las ausencias del migrante, es mayor la dependencia del grupo doméstico del envío de remesas, mientras que los periodos cortos refuerzan las oportunidades de inversión productiva de las remesas.

Zazueta (1981) establece una relación entre el número de trabajadores que contribuyen al ingreso familiar y el número de migrantes de retorno que utilizan el dinero que ahorraron en Estados Unidos para invertirlo, así como una relación inversa entre el número de contribuyentes al gasto familiar y la decisión de destinar el dinero al consumo. El conocer el curso de vida individual y familiar en el cual ocurrió la decisión de migrar es fundamental para comprender la movilidad ocupacional de los migrantes retornados. 
La segunda dimensión analítico temporal son las condiciones en que fue vivida la experiencia migratoria; es decir, las características de los actos migratorios que incentivaron las acumulaciones de activos. Muchos de los migrantes no pretenden hacerse ciudadanos estadunidenses cuando están en Estados Unidos; sin embargo consideran importante regularizar su estancia allí, ya que así podrían invertir sus ahorros en ese país y emprender algún negocio en su lugar de origen (Baca y Dexter, 1981). Los logros ocupacionales de los migrantes de retorno en México dependen de la experiencia laboral que hayan adquirido en Estados Unidos. La acumulación de activos de capital humano o físico está estrechamente ligada al tipo de trabajo que desempeñaron en ese país.

Por otro lado, Durand et al. (1996a) apuntan que la variable explicativa más importante de la experiencia migratoria es el ingreso mensual, pues éste determina la capacidad de ahorro y de envío de remesas. De su ingreso mensual el migrante ha de descontar lo que gasta en alimentación, renta e impuestos, y el excedente será el ahorro que podría invertir en México. El tiempo en Estados Unidos es otro elemento fundamental para la acumulación. Las oportunidades de aprender un oficio o recibir capacitación laboral están asociadas a la duración de la estancia en el país vecino, y contribuyen en la transformación de la posición ocupacional al regreso (Papail y Arroyo, 2004).

Ahora bien ¿tiene alguna influencia la formación del capital social en el logro de acumulaciones de capital físico y humano? Por un lado, Mooney (2004) argumenta que las redes sociales de los migrantes en Estados Unidos incrementan las posibilidades de que los individuos a su regreso a México inviertan sus ahorros o remesas en actividades económicas, ya que pueden acceder a información sobre los mercados adonde pueden dirigir sus esfuerzos de inversión. Por otro lado, el acceso a mejores trabajos dentro del mercado laboral en Estados Unidos está relacionado con las redes sociales. Los migrantes conocen mejores ofertas de trabajo a partir de otros migrantes (Zenteno, 2000).

Además, los migrantes que desean realizar una inversión productiva en sus lugares de origen pueden usar esas redes para enviar el dinero ahorrado o conocer en voz de otros migrantes en dónde y cómo invertirlo de mejor manera, con mayores rendimientos. Los migrantes que se encuentran por largos periodos en Estados Unidos y que se reúnen con otros migrantes de su país de origen en clubes o redes son más propensos a invertir sus ahorros a su regreso. Esta vinculación con 
organizaciones de migrantes les representa la conservación de su membresía y su estatus social dentro de la comunidad de origen. ${ }^{17}$

De igual forma, al considerar las dimensiones -antes de migrar y durante la experiencia laboral- es obligado discutir la influencia del regreso y las oportunidades socioeconómicas del lugar de destino. Un factor importante en la propensión a regresar a México es el tiempo de residencia en el país vecino. El proyecto de reinstalarse en México se debilita con el tiempo. El residir legalmente en Estados Unidos hace que disminuyan las posibilidades de regresar a México y también el número de quienes deciden hacerlo (Massey et al., 1991).

Se ha dicho que las variables clave en el proceso de emigración de retorno son la posesión de propiedad, la edad y el estado civil. Cuando una familia posee una casa en México o maneja alguna empresa productiva, aumenta sustancialmente la probabilidad del regreso (Massey et al., 1991). Quienes retornan en etapas de expansión familiar podrían verse imposibilitados para buscar un trabajo acorde con las habilidades y destrezas laborales que aprendieron en el extranjero. El curso de vida individual y familiar del migrante es un elemento mediador de las movilidades ocupacionales en el país de origen.

Respecto a las oportunidades, las condiciones de los contextos rurales y urbanos se asocian a la movilidad ocupacional de los migrantes a su regreso, ya que no todas las experiencias migratorias brindan elementos de capacitación que puedan aprovecharse en el lugar de origen. En algunos casos la labor que se desempeña en el lugar de destino es relativamente compleja y en otros sus funciones son irrelevantes.

Durand et al. (1996b) apuntan que los contextos económicos dinámicos en donde los salarios son altos, hay ciertas formas de autoempleo y una gran participación laboral femenina en el sector industrial, son atractivos para la inversión migrante. Los sistemas de comunicación (principalmente la red carretera) representan accesos a mercados de consumo para los bienes y servicios que producen los migrantes; asimismo la presencia de una institución financiera (banco) dentro de la comunidad fomenta en ellos la idea de enviar y ahorrar su dinero.

En contraste, las comunidades cuyas economías son mayoritariamente agrícolas difícilmente atraen la inversión a partir de las remesas

\footnotetext{
${ }^{17}$ García Zamora (2005) ha estudiado las remesas y las formas de organización productiva de los migrantes en Zacatecas y ha examinado la conformación de los activos relacionados con el capital físico y humano y su aprovechamiento dentro de las comunidades de origen.
} 


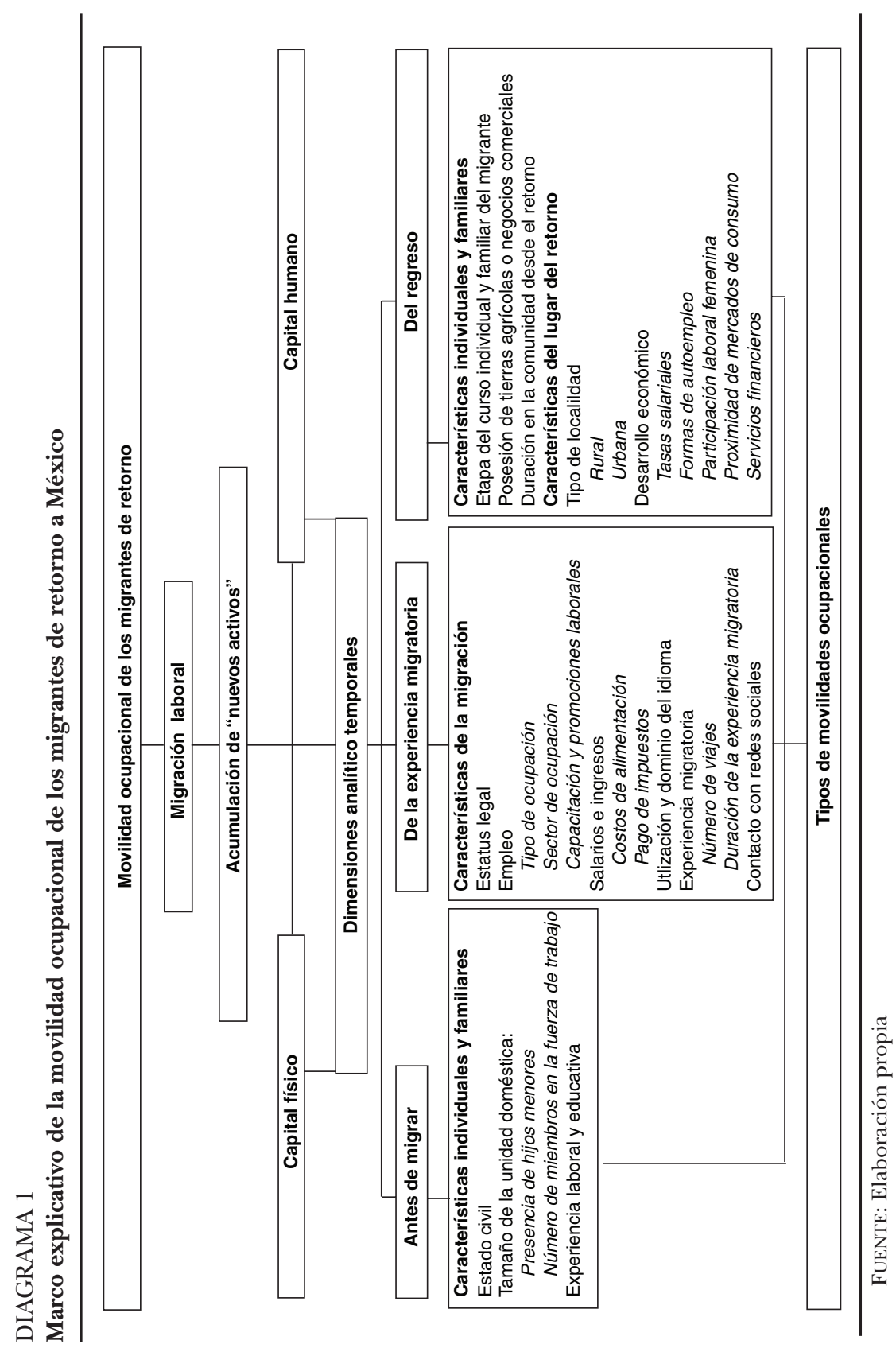


(Durand, 1996b). Sin embargo, cuando las familias migrantes poseen ejidos, éstos constituyen un nicho en donde pueden ser aprovechados dichos recursos monetarios. Las áreas rurales con escasez de factores productivos ofrecen pocos rendimientos a las inversiones de los migrantes. En las comunidades poco pobladas son menos rentables los negocios financiados con el ahorro de los que regresan (Lindstrom, 1996).

Las características del mercado y de las oportunidades de inversión en la comunidad de origen son determinantes para la posible inversión del migrante de retorno. Hay evidencias del caso mexicano sobre el uso de las remesas que apoyan la idea de que las motivaciones de los migrantes reflejan la estructura económica de su comunidad de origen (Lindstrom, 1996).

En suma, el marco explicativo de la movilidad ocupacional de los migrantes de retorno en México está dado por tres dimensiones analítico temporales que estructuran las formaciones de capital humano o físico. Éstas determinan las formas de reinserción laboral de los migrantes $y$, por ende, los patrones de movilidad ocupacional que experimentan.

\section{Reflexiones finales}

Nuestra investigación se centró en la construcción de un marco explicativo que lleve a entender la movilidad social de los migrantes de retorno. El análisis incluyó tres dimensiones analítico temporales: antes de migrar, la experiencia migratoria, y el regreso. En un contexto en que la migración internacional responde a cuestiones laborales es necesario generar conocimientos sistemáticos que den la posibilidad de conocer cuáles son las consecuencias de la experiencia laboral en el extranjero en los mercados de trabajo del país de origen. La migración a Estados Unidos puede representar una oportunidad para adquirir "nuevos activos" de capital humano y físico.

Para analizar las formaciones de estos nuevos activos a partir de la experiencia migratoria se deben tomar en cuenta tres dimensiones analítico temporales. La primera contempla el momento en el que ocurrió el desplazamiento. Las inversiones productivas y las formas de vinculación con los mercados de trabajo al regreso están mediadas por el curso de vida individual y familiar del migrante. La segunda dimensión toma en cuenta la manera en que fue vivida la experiencia migratoria en Estados Unidos. La acumulación de activos de capital humano 
o físico está determinada por las características que asume la migración internacional. La última dimensión está constituida por las oportunidades socioeconómicas del lugar adonde regresan los emigrantes. Los contextos menos dinámicos escasamente atraerán a los migrantes, puesto que son pocos los incentivos para invertir allí los ahorros y las remesas, y porque las habilidades laborales tienen poca utilidad en el marco de oportunidades.

Cabe destacar que el marco interpretativo aquí propuesto podría ser puesto a prueba con bases de datos que contengan información acerca de las trayectorias laborales y migratorias de los individuos. Afortunadamente, el Proyecto Mexicano sobre Migración (MMP por su acrónimo en inglés) ha recopilado evidencia empírica de una muestra de población migrante y no migrante de 114 comunidades mexicanas. Asimismo la Encuesta Retrospectiva sobre Migración y Empleo en Estados Unidos (ERMEU) contiene datos sociodemográficos de la población que retorna a contextos metropolitanos del país (Ciudad de México, Guadalajara y Monterrey).

Finalmente, la problemática que hemos abordado apunta a nuevas interrogantes entre ellas la movilidad ocupacional de las mujeres que regresan, y la comparación de los logros laborales de los hijos con los de sus padres migrantes (movilidad intergeneracional). En los países expulsores se abre una interesante línea de investigación acerca de los efectos o repercusiones de la migración en materia laboral.

\section{Bibliografía}

Altamirano, Teófilo (2004), "Sostenibilidad de la migración transnacional: los casos de Perú y Ecuador”, ponencia presentada el Seminario Permanente sobre Migración Internacional, séptima jornada, México, Somede/ Colef/El Colegio de México.

Ariza, Marina y Orlandina de Oliveira (2005), "Unión conyugal e interrupción de la trayectoria laboral de las trabajadoras urbanas en México" en MarieLaure Coubés, Maria Eugenia Zavala de Cosío y René Zenteno (coords.), Cambio demográfico y social en el México del siglo XXI, México, Cámara de Diputados/Instituto Tecnológico y de Estudios Superiores de Monterrey/ El Colegio de la Frontera Norte/Miguel Ángel Porrúa, pp. 429-451.

Baca, Reynaldo y Bryan Dexter (1981), "Mexican Undocumented Workers in the Binational Community: a Research Note", International Migration Review, vol. 15, num. 4, pp. 737-748. 
Behrman, Jere, A. Gaviria y Miguel Zsékely (2000), "Social Mobility: Concepts and Measurement", en N. Birdsall y Carol Graham (eds.), New Markets, New Opportunities? Economic and Social Mobility in a Changing World, Washington, Brookings Institution Press, pp. 3-21.

— - A. Gaviria y Miguel Székely (2002), "Intergenerational Mobility in Latin America”, Economía, Journal of the Latin American and Caribbean Economic Association, vol. 2, núm. 1, p. 44.

Birdsall, N. y Carol Graham (2000), "Mobility and Markets: Conceptual Issues and Policy Questions", en N. Birdsall y Carol Graham (eds.), New Markets, New Opportunities? Economic and Social Mobility in a Changing World, Washington, Brookings Institution Press, pp. 3-21.

Canales, Alejandro (2002), "Migración y trabajo en la era de la globalización: el caso de la migración México-Estados Unidos en la década de 1990”, Papeles de Población, año 8, núm. 33, pp. 47-80.

— (2005), "El papel económico y productivo de las remesas en México. Una visión crítica", ponencia presentada en el Seminario Internacional: Problemas y Desafíos de la Migración y el Desarrollo en América, Morelos, México, Red Internacional de Migración y Desarrollo/CRIM-UNAM/Centro de Estudios sobre América Latina y el Caribe, CERLAC/York University.

Cerrutti, Marcela (1997), Doping with Opposing Pressures: a Comparative Analysis of Women's Intermittent Participation in the Labor Force in Buenos Aires and Mexico City, tesis de doctorado en Sociología, Texas, Universidad de Texas en Austin.

Cobo, Salvador (2004), Migración circular a Estados Unidos y la movilidad ocupacional de los jefes de hogar migrantes en México. Regresando a casa, tesis de maestría en Demografía, Centro de Estudios Demográficos y Urbanos, El Colegio de México.

Conapo (2001), "La migración de mexicanos a Estados Unidos", La población de México en el nuevo siglo, México, Consejo Nacional de Población, pp. $77-94$.

- (2002), Índices de intensidad migratoria México-Estados Unidos, México, Consejo Nacional de Población.

— (2005), Migración México-Estados Unidos. Panorama regional y estatal, México, Consejo Nacional de Población.

Conway, Dennis y Jeffrey H. Cohen (1998), "Consequences of Migration and Remittances for Mexican Transnational Communities”, Economic Geography, vol. 74, núm. 1, pp. 26-44.

Corona, Rodolfo (2004), "Los migrantes mexicanos y las remesas que envían", en Germán Zárate (coord.), Remesas de los mexicanos y centroamericanos en Estados Unidos: problemas y perspectivas, México, El Colegio de la Frontera Norte, pp. 25-63.

— y Rodolfo Tuirán (2000), "Dimensión de la migración a Estados Unidos desde la perspectiva de los hogares", en Rodolfo Tuirán (coord.), Migración México-Estados Unidos: opciones de política, México, Conapo/SER, pp. 79-117. 
Cortés, Fernando y Agustín Escobar (2003), "Movilidad social intergeneracional en los años de la reforma económica: un estudio del México urbano", Revista de la CEPAL, núm. 42.

Cruz, P. Rodolfo (1994), "Volatilidad en el empleo femenino: características individuales y del hogar", Frontera Norte, vol. 6, núm. 12, pp. 25-39.

- (2002), "Los mexicanos en Estados Unidos. Empleo y migración”, en Demos. Carta Demográfica sobre México, núm. 15, pp. 33-34.

Durand, Jorge (2005), "De traidores a héroes: políticas emigratorias en un contexto de asimetría de poder", en Raúl Delgado y Beatriz Knerr (coords.), Contribuciones al análisis de las migración internacional y el desarrollo regional en México, México, Cámara de Diputados del H. Congreso de la Unión/ Miguel Ángel Porrúa/UAZ, pp. 15-38.

—_ y Douglas Massey (2003), Clandestinos. Migración México-Estados Unidos en los albores del siglo XXI, México, Miguel Ángel Porrúa/UAZ.

__ William Kandel, Emilio Parrado y Douglas Massey (1996a), "International Migration and Development in Mexican Communities”, Demography, vol. 33, núm. 2.

— pment: a Reconsideration of the Mexican Case", International Migration Review, vol. 30, núm. 2, pp. 423-444.

Colef (2001), Encuesta sobre Migración en la Frontera Norte de México 1998-1999, México, STPS/Conapo/Colef/INM.

Escobar, Agustín (2001), Nuevos modelos económicos: ¿nuevos sistemas de movilidad social?, Chile, CEPAL/ECLAC (Políticas Sociales, División de Desarrollo Social).

— y M. Martínez (1987), "Mercados de trabajo regionales y migración a Estados Unidos. La pequeña industria y la migración internacional en Guadalajara”, en Memoria del Seminario sobre Migración Internacional y el Desarrollo Económico, México, Conapo, pp. 71-90.

Feindt, Waltraut y Harley L. Browning (1972), "Return Migration: its Significance in a Industrial Metropolis and Agricultural Town in Mexico", International Migration Review, vol. 6, núm. 2, pp. 158-165.

Filgueira, Carlos (2000), La actualidad de viejas temáticas: sobre los estudios de clase, estratificación y movilidad social en América Latina, Chile, CEPAL.

García Zamora, Rodolfo (2005), "Los retos de las organizaciones de migrantes mexicanos en Estados Unidos: el caso de las federaciones de clubes de zacatecanos", ponencia presentada en el Seminario Internacional: Problemas y Desafíos de la Migración y el Desarrollo en América, México, Red Internacional de Migración y Desarrollo, CRIM, UNAM/ Centro de Estudios sobre América Latina y el Caribe/CERLAC/York University.

Goldscheider, Calvin (1987), "Migration and Social Structure: Analytic Issues and Comparative Perspectives in Developing Nations", Sociological Forum, vol. 2, núm. 4, pp. 674 - 696 . 
INEGI (2000), Censo de población y vivienda, 2000, México, Instituto Nacional de Estadística, Geografía e Informática.

- (2002), Encuesta Nacional de Empleo, 2002, México, Instituto Nacional de Estadística, Geografía e Informática.

Massey, Douglas, Rafael Alarcón, Jorge Durand y Humberto González (1991), Los ausentes. El proceso social de la migración internacional occidental de México, México, Consejo Nacional para la Cultura y las Artes/Alianza.

Massey, Douglas, Kristin Espinosa y Jorge Durand (1998), "Dinámica migratoria entre México y Estados Unidos", en René Zenteno (coord.), Población, Desarrollo y Globalización. VReunión de Investigación Sociodemográfica en México, vol. 2, México, Somede/Colef.

Mooney, Margarita (2004), "Migrant's Social Capital and Investing Remittances in Mexico", en Jorge Durand y Douglas Massey (eds.), Crossing the Border. Research from the Mexican Migration Project, Estados Unidos, Russel Sage Foundation.

Lindstrom, David (1996), "Economic Opportunity in Mexico and Return Migrant from United States, Demography, vol. 33, núm. 3, pp. 357-374.

— y Kim Sunghoon (2002), "Temporary Migration to the United States and the Pathways to Upward Occupational Mobility in Mexico", ponencia presentada en el Annual Meetings of PAA, Florida, Estados Unidos.

Pacheco, Edith (2005), "La movilidad ocupacional de los hijos frente a los padres”, en Marie-Laure Coubés, María Eugenia Zavala de Cosío y René Zenteno (coords.), Cambio demográfico y social en el México del siglo XXI, México, Cámara de Diputados/Instituto Tecnológico y de Estudios Superiores de Monterrey/El Colegio de la Frontera Norte/Miguel Ángel Porrúa, pp. 429-451.

Papail, Jean (2002), "De asalariado a empresario: la reinserción laboral de los migrantes internacionales en la región centro-occidente de México", Migraciones Internacionales, vol. 1, núm. 3, julio-diciembre, pp. 79-102.

— y Jesús Arroyo (2004), Los dólares de la migración, México, Universidad de Guadalajara/Institut de Recherche pour le Devéloppement/Profmex/ Juan Pablos.

Parrado, Emilio (2003), "Reversal of Opportunities: Neoliberal Policies and Intra-Generational Class Mobility in Mexico", documento de trabajo, Durham, Department of Sociology of Duke University.

- (2004), "U.S. Migration, Home Ownership and Housing Quality", en Jorge Durand y Douglas Massey (eds.), Crossing the Border. Research from the Mexican Migration Project, Estados Unidos, Russel Sage Foundation.

— y René Zenteno (2002), "Gender Differences in Union Formation in Mexico: Evidence from Marital Search Models”, Journal of Marriage and Family, núm. 64, pp. 756 -773.

Peinador, Rocío (2001), Madres, esposas y trabajadoras: un estudio sobre la primera salida del mercado laboral y su relación con la primera unión y el primer nacimien- 
to en mexicanas de tres cohortes, tesis de maestría en Población, México, Facultad Latinoamericana de Ciencias Sociales.

Solís, Patricio (2002), Structural Change and Men's Work Lives: Transformations in Social Stratification and Occupational Mobility in Monterrey, Mexico, tesis de doctorado, Austin, University of Texas.

(2003), "Vidas laborales entre la continuidad y el cambio social: trayectorias masculinas en Monterrey”, Estudios Demográficos y Urbanos, vol. 18, núm. 3, pp. 559-595.

- (2005), "Cambio estructural y movilidad ocupacional en Monterrey", Estudios Sociológicos, vol. 23, núm. 1, pp. 43-73.

Tuirán, Rodolfo (1997), "La migración de mexicanos a Estados Unidos: patrones de continuidad y cambio”, Demos. Carta Demográfica sobre México, núm. 10.

Zazueta, César (1981), "Los migrantes y la utilización del dinero enviado o llevado a sus comunidades de origen", texto presentado en el ciclo de conferencias Problemas Socioeconómicos de México. Migración, México IPN.

Zenteno, René (2000), "Redes migratorias: ¿acceso y oportunidades para los migrantes?”, en Rodolfo Tuirán (coord.), Migración México-Estados Unidos. Opciones de política, México, Conapo/Secretaría de Gobernación/ Secretaría de Relaciones Exteriores, pp. 227-246.

- (2003), "Polarización de la movilidad social en México", Demos. Carta Demográfica sobre México, núm. 16.

y Patricio Solís (2006), "Continuidades y discontinuidades de la movilidad ocupacional en Monterrey”, Estudios Demográficos y Urbanos, vol. 21, núm. 3, pp. 515-546. 